\title{
AS EXPERIÊNCIAS DO RACISMO PERCEBIDAS PELOS FAMILIARES DE PESSOAS COM DOENÇA FALCIFORME NA REDE DE ATENÇÃO NA CIDADE DE FEIRA DE SANTANA E SALVADOR.
}

\author{
Jackeline Sena Nunes'; $^{1}$ Edna Maria de Araújo²; Aline Silva Gomes Xavier ${ }^{3}$ \\ Evanilda Souza de Santana Carvalho ${ }^{4}$; Kevin Góes Lobo ${ }^{5}$ \\ 1. Bolsista PIBIC/CNPq, Graduando em Medicina, Universidade Estadual de Feira de Santana, e-mail: \\ kelmed2@yahoo.com.br \\ 2. Orientador, Departamento de Saúde, Universidade Estadual de Feira de Santana, e-mail: \\ ednakam@gmail.com \\ 3. Participante do projeto, Departamento de Saúde, Universidade Estadual de Feira de Santana, e-mail: \\ asgx@ig.com.br \\ 4. Participante do projeto, Departamento de Saúde, Universidade Estadual de Feira de Santana, e-mail: \\ evasscarvalho@yahoo.com.br \\ 5. Participante do projeto, Departamento de Saúde, Universidade Estadual de Feira de Santana, e-mail: \\ keevinlobo@hotmail.com
}

PALAVRAS-CHAVE: doença falciforme; população negra; racismo e saúde.

\section{INTRODUÇÃO}

A presença do Estado teve uma representatividade significativa na configuração sociorracial, no momento de transição do trabalho escravo para o trabalho livre, sem a presença de qualquer política pública integrativa para os ex- escravizados. Sendo assim, a falta de isonomia entre os diferentes segmentos populacionais segundo raça e etnia, aponta para o fato da população negra estar sempre em desvantagens no que se refere à maioria dos indicadores de situação econômica e de saúde (ARAUJO, 2010).

Portanto a Doença Falciforme (DF) é também relacionada ao campo da saúde da população negra como forma de reconhecer a invisibilidade histórica da enfermidade, que diversos pesquisadores e o próprio Ministério da Saúde, consideram como fruto do racismo institucional atrelado a doença devido a sua maior incidência na população negra (CARVALHO, 2015; XAVIER, 2011).

A DF é a doença crônica e hereditária mais comum do Brasil, com predomínio em afrodescendentes, que provoca grande impacto no cotidiano da vida das pessoas adoecidas e suas famílias trazendo repercussões em diversas dimensões, como nas interações sociais e familiares (ARAÚJO, 2013).

Desta forma, têm-se como objetivo conhecer quais as experiências do racismo percebidas pelos familiares de pessoas com DF na rede de atenção à saúde dos municípios de Feira de Santana e Salvador.

O presente estudo justifica-se pela elevada prevalência da DF na população afrodescendente, predominante em Feira de Santana-Ba e Salvador-Ba, visto ser considerada uma questão de saúde pública.

Ter ciência da percepção do racismo nas praticas do cuidado, fornecida aos usuários com DF, torna-se relevante uma vez que a pesquisa irá contribuir tanto para a capacitação dos profissionais quanto para a fundamentação de políticas públicas em relação a saúde da população negra.

\section{METODOLOGIA}

Este estudo é subprojeto do projeto matriz "Avaliação da Atenção à Saúde da População Negra e a Intersecção do Racismo Sobre as Práticas de Cuidado em Estados do Nordeste e do Sudeste brasileiro" que foi aprovado pelo CEP da UEFS, sob parecer 1.423.346, CAAE: 48607315.6.1001.0053.

Foi desenvolvido um estudo na perspectiva da abordagem qualitativa, de caráter exploratório, uma vez que pretendeu compreender quais as experiências do racismo 
percebidas pelos familiares de pessoas com DF na rede de atenção à saúde. O estudo foi realizado no Centro de Referência à Pessoa com Doença Falciforme, localizado no bairro Cidade Nova em Feira de Santana - BA e na Associação Baiana das Pessoas com Doença Falciforme (ABADFAL), localizado no SESC Aquibadã na Av. Pres. Castelo Branco- Nazaré, Salvador-BA.

Os sujeitos deste estudo foram os familiares (acima de 18 anos), das pessoas com doença falciforme, que frequentavam o Centro de Referência à Pessoas com Doença Falciforme em Feira de Santana e a ABADFAL. Foi excluído da pesquisa familiares que não participavam em algum momento da vida cotidiana do adoecido e aqueles que se recusaram fazer a entrevista.

Para garantir o anonimato dos participantes de estudo, foram utilizadas siglas para retratá-los. As mulheres são chamadas de "M" e os homens de "H". As entrevistas só foram realizadas após os sujeitos serem informados sobre o objetivo do estudo e consentirem previamente a realização das mesmas por meio de assinatura do Termo de Consentimento Livre e Esclarecido (TCLE).

A coleta de dados foi realizada de outubro de 2016 a fevereiro de 2017. Para a coleta de dados, utilizou-se a técnica de entrevista semiestruturada. As falas foram submetidas à análise de conteúdo, conforme proposto por Laurence Bardin (2009). As entrevistas foram realizadas em ambientes restritos, sempre garantindo a privacidade dos entrevistados e foram gravadas e posteriormente transcritas.

\section{RESULTADOS E/OU DISCUSSÃO}

Participaram do estudo 14 pessoas, sendo 13 mulheres e um homem, a faixa etária predominante foi 24 e 59 anos, sendo uma em união estável, sete solteiras, quatro casadas e uma viúva Do total de participantes dois tinham união estável, sete eram solteiras, quatro casadas e uma viúva. A raça/cor predominante foi preta, seguida de parda, sendo seis entrevistados naturais do município de Feira de Santana- Ba e oito do município de Salvador-BA.

Quanto à ocupação, obtiveram-se quatro do lar, um agricultor, um desempregado, uma dona de casa, um autônomo, duas professoras, um estudante, uma cabeleireira e um em serviços gerais, sendo a maioria de baixa renda e baixa escolaridade.

Em relação a religião a católica e a protestante foram as mais citadas. Quanto à caracterização da DF, o tipo predominante referido pelos entrevistados foi o HbSS.

Posterior a análise dos dados coletados de forma estruturada, foi realizado a análise dos discursos dos familiares, com as seguintes categorias:

\section{Familiares reconhecem a invisibilidade da Doença Falciforme nas redes de saúde e nas práticas do cuidado.}

É notável na rede de atenção um desconhecimento ou falta de capacitação dos profissionais de saúde no que tange a DF. Os familiares relatam que é evidente a invisibilidade da doença através das praticas de cuidado pelos profissionais. A narrativa a seguir demonstra alguns desses enfrentamentos:

"[...] já tinha acontecido vários casos de crianças que tavam vindo a óbito por inexperiência dos profissionais...elas tinham necessidade de estar no atendimento e eles não tiveram essa percepção...”. (M7)

“[...] o interessante da invisibilidade é exatamente ela vai se expressar exatamente por isso, na hora que o profissional não conhece a doença“"[...]É assim...da sutileza, da finesse do racismo, ele não se apresenta de uma forma escancarada, mas ele vai se apresentar principalmente na invisibilidade da doença falciforme, não vamos ouvir falar do traço falciforme, mesmo que eu tenho um livro de genética. Então, é como se a doença falciforme fosse algo que pairasse na nossa sociedade e onde de forma muito periférica.”. (H11) 
Observa-se ainda que os familiares acabam não tendo suas necessidades de saúde reconhecidas e tratadas adequadamente devido a falta de percepção dos profissionais.

"[...] tem outros que nem pergunta o que é que ele tem, já foi tratado como simplesmente uma enxaqueca ou como qualquer outra coisa, qualquer outra doença". (M9)

"[...]Se a pessoa não conhece o que é a doença porque fica dizendo que é hepatite, que é leucemia, que é isso e aquilo, fica dando nome as doenças que eles nem conhecem o que é?". (M12)

\section{Familiares identificam barreiras no acesso aos serviços de saúde}

Um aspecto importante citado pelos entrevistados é a barreira geográfica enfrentada por seu familiar as redes de atenção, dificultando seu ingresso nos serviços de saúde e provocando uma peregrinação em busca de cuidados de emergência.

"Eu acho que numa policlínica de um bairro tinha que ter umas coisas assim, mais né? Uma coisa assim de mais urgência, que não precisaria deslocar pra outros lugares...emergência perto de casa...então quando não atendem do jeito que deveria ser, né? Eu acho que é um tipo de preconceito" (M5)

Apontam ainda que os profissionais de saúde desconsideram o relato do seu parente adoecido, e agem com atitudes de descrédito, negligencia e descaso; minimizando suas queixas. Fatos que podem ser vistos pelos relatos a seguir:

"[...] é porque quando eu chego nas policlínicas demoram de atender ela, a pessoa fala assim de boca " ah essa menina tem essa anemia nada" né?porque a gente falando assim eles não acredita. Acho que é isso, a discriminação é isso...". (M6)

"Na rede de saúde tinha porque a questão de demorar de atender, da gente chegar pra ela ta sentindo dores fortes e os médicos, as pessoas de lá da saúde passava e achava que era normal, que ela tava fingindo, alguma coisa assim". (M12)

\section{Familiares identificam a presença de um racismo interpessoal e institucional das organizações de saúde.}

É observado nos discursos dos familiares uma sensação de desamparo governamental. Eles consideram que há um fracasso das entidades e organizações no que diz respeito ao investimento de pesquisas no campo da DF, aos programas de atenção e a falta de inclusão da questão racial nos aparelhos de formação.

"[...]quando eu não desenvolvo programas, não coloco essa doença como prioritária, quando eu pego essa doença que é de maior incidência na Bahia 1 em cada 650 e a secretaria de saúde, estado ou a secretaria de município não colocam no seu plano de formação, de capacitação de profissionais, é uma forma de racismo institucional. Então muitas vezes eu vou ter as formas indiretas que vão sustentar esse racismo dentro do sistema de saúde, tanto de invisibilizar a doença, quanto de não prover, né? [...]tem uma fala de uma médica americana, ela coloca exatamente isso ' mesmo não sendo muito confortável perceber isso, temos que admitir que o fato da doença falciforme está ligada a população negra faz com que os recursos para a pesquisa, os recursos para o tratamento sejam menores"'. (H11)

Os familiares relatam que muitas vezes são tratados com desprezo pelo profissional por já conhecerem o manejo da dor, sendo isso visto como uma afronta.

“[...] meu tio chegou com dor na emergência... o profissional não sabia, ele não falou isso, mas ele não sabia lidar com a situação, era perceptível que ele não tinha conhecimento, e aí meu tio começou a ensiná-lo o que ele deveria fazer porque ele já tinha feito escala de dor, etc e tal...e aí ele se sentiu ofendido pelo fato de um paciente estar ensinando a ele como agir e acabou interferindo com meu tio... e eu lá só assistindo e ele tentando 
explicar...'eu preciso de soro, eu preciso hidrolisar, eu preciso de um médico"'. (M8)

É observado também atitude e discurso com cunhos preconceituosos por parte dos profissionais de saúde devido a cultura e origem racial ou étnica dos pacientes e familiares. Sendo demonstrado na fala a seguir:

"[...]Exemplo de uma caso de marcou muito... ela tava tendo muita febre, levamos no hospital e chegando lá o médico hematologista nos perguntou qual era os medicamentos que ela estava tomando , numa relação de confiança com o médico, nós dissemos estamos também fazendo tratamento homeopático e alguns medicamentos naturais e aí ele olhou pra mim e disse “ e vai levar ela no terreiro de candomblé quando? Aí ele usa a religião de matriz africana como um dos elementos, mas mais do que isso é o descredenciamento da minha fala, né? E aí eu não tenho como não imaginar que ele relaciona logo isso porque ele ta vendo um corpo negro ali na frente dele". (H11)

\section{CONSIDERAÇÕES FINAIS}

Os resultados evidenciaram que os familiares dos pacientes com DF vivenciam peregrinação nos diversos serviços de saúde em busca de cuidados; e quando conseguem tais serviços são tratados com descaso e descrédito, o que leva a minimização dos sintomas referidos por seus entes queridos por parte dos profissionais de saúde. Há uma ausência de prioridades na agenda política, a falta de qualificação dos profissionais e carência de recursos financeiros destinados ao cuidado e manejo da doença, sendo apontado como um tipo de discriminação, pois nega o acesso aos serviços que teoricamente seria direito de todos. Portanto, é primordial que os profissionais de saúde busquem se colocar no lugar da pessoa com a doença falciforme e seus familiares, tenham respeito com a singularidade de cada um e comprometam-se em exercerem as suas profissões, tendo sensibilidade e compreensão. É também indispensável que os gestores e os profissionais desenvolvam meios que garantam um acesso, acolhimento e se sintam corresponsáveis no atendimento às pessoas com doença falciforme nas redes de saúde.

\section{REFERÊNCIAS}

ARAUJO, E. M. et al. Desigualdades em saúde e raça/cor da pele: revisão da literatura do Brasil e dos Estados Unidos (1996-2005). Saúde Coletiva vol. 7, n. 40, pg. 116-121, 2010.

CARVALHO, E. M. M. S; CAMARGO, S. L. Doença falciforme nas pesquisas em enfermagem: uma revisão integrativa. Revista Baiana de Enfermagem, Salvador, vol. 29, n. 1, p. 86-93, jan./mar. 2015.

XAVIER, A. S. G. Experiências reprodutivas de mulheres com anemia falciforme. Dissertação (Mestrado em Enfermagem) - Escola de Enfermagem, Universidade Federal da Bahia, Salvador, 2011.

ARAÚJO, E. M. Núcleo de Pesquisa e Extensão Junto à População com Doença Falciforme na segunda maior cidade do Estado da Bahia. Revista Extendere, v. 1, p. 4860, 2013.

BARDIN, L. Análise de conteúdo. Lisboa, Portugal: Edições 70, 2009. 